\title{
SEMIOTÉCNICA NEUROLÓGICA
}

\author{
TECHNIQUE OF THE NEUROLOGIC EXAMINATION
}

José Geraldo Speciali

Docente do Departamento de Neurologia, Psiquiatria e Psicologia Médica da Faculdade de Medicina de Ribeirão Preto da Universidade de São Paulo.

CorResPondÊnCIA: Departamento de Neurologia, Psiquiatria e Psicologia Médica da Faculdade de Medicina de Ribeirão Preto - Campus Universitário - Ribeirão Preto - SP - CEP: 14048-900 - Fax: (016) 633.0866

SPECIALIJG Semiotécnica neurológica. Medicina, Ribeirão Preto, 29: 19-31, jan./mar. 1996.

RESUMO: O autor descreve, suscintamente, os principais passos do Exame Neurológico. Os objetivos principais são iniciar os estudantes da área médica, especialmente os de Medicina, nas técnicas do Exame Neurológico e padronizá-las no Hospital das Clínicas da Faculdade de Medicina de Ribeirão Preto da Universidade de São Paulo.

UNITERMOS: Anamnese. Diagnóstico Neurológico. Exame Físico. Exame Neurológico. Neurologia.

\section{Material necessário para realizar o exame neurológico:}

Para atender aos objetivos do ensino neurológico, é necessário que os alunos disponham de instrumentos adequados que serão exigidos, por serem indispensáveis ao exame clínico. Consideramos essencial que todo estudante tenha, para uso pessoal, o seguinte material:

1. Abaixador de língua

2. Algodão

3. Alfinete

4. Estilete de ponta romba

5. Fita métrica

6. Lanterna de bolso

7. Martelo de reflexos.

8. Diapasão de 128 ou 256 Hertz

9. Oftalmoscópio.

\section{Roteiro e Técnica do Exame Neurológico}

\section{1 - Anamnese:}

1.1. Queixa e duração.

1.2. História da moléstia atual.

1.2.1. Início:súbito, insidioso.

1.2.2. Evolução: estacionária. Regressiva. Progressiva. Paroxística. Recidivante Ondulante.

1.2.3. Tratamentos anteriores.

O início súbito deve ser comparado, para o paciente entender bem, como sendo parecido com o estalar de um trovão e deve ser diferenciado, por exemplo, de um início rápido, mas que dure alguns segundos ou poucos minutos. O primeiro caso lembra a ruptura de um aneurisma cerebral, enquanto que o segundo lembra a instalação de acidente vascular cerebral isquêmico.

O início insidioso lembra lesão expansiva ou doenças, lentamente, progressivas como a Doença de Parkinson e a Doença de Alzheimer.

O tipo de evolução ajuda no raciocínio do diagnóstico etiológico. 
A evolução estacionária indica uma doença que deixa seqüela, como por exemplo um trauma medular ou hemorragia cerebral. Se no decorrer dos meses (dias), houver melhora dos sinais/sintomas, a evolução é chamada de regressiva.

A evolução progressiva lembra patologias que aumentam com o tempo, como as doenças degenerativas e as lesões expansivas.

A evolução paroxistica e recidivante diferem apenas na duração dos sintomas. No primeiro tipo, os sinais/sintomas devem durar por minutos ou poucas horas (ex. crise epiléptica, enxaqueca) enquanto no segundo tipo, os sinais/sintomas poderão durar meses (ex. Esclerose Múltipla) e depois regredir, total ou parcialmente.

A evolução ondulante caracteriza algumas doenças que sofrem influência de fatores internos, como a hipo ou hiperglicemia, uremia, amonemia ou externos como o frio (afetando a circulação cerebral, por exemplo).

1.3. Interrogatórios: Cefaléias. Vômitos. Alterações visuais. Convulsões. Desmaios. Dor. Parestesias. Anestesias. Fraqueza muscular. Paralisias. Atrofias. Tremores. Movimentos involuntários. Alteração de marcha. Fala. Escrita. Distúrbios psíquicos. Alterações do apetite. Emagrecimento. Alterações dos esfíncteres. Distúrbios sexuais.

1.4. Antecedentes Pessoais: Condições de gestação: moléstias, febre, uso de medicamentos, traumas, exames radiológicos, tratamentos por radiações. Condições de nascimento e neonatais: tipo de parto, anoxia cerebral, choro, sucção, convulsões, icterícia, complicações cardio-respiratórias. Desenvolvimento psicomotor. Rendimento escolar e no trabalho. Traumatismos crânio-encefálicos. Moléstias infecciosas. Teníase. Moléstias venéreas. Condições de nutrição. Etilismo. Tabagismo. Drogas e Tóxicos. Convulsões.

1.5. Antecedentes familiares: Antecedentes obstétricos maternos ( $\mathrm{n}^{\mathrm{o}}$ de gravidezes, abortos e filhos). Moléstias semelhantes e neurológicas na família. Levantamento familiar. Consangüinidade dos pais. Verminose.

\section{Exame físico geral}

2.1. Tipo constitucional. Mucosas. Estado de nutrição.

2.2. Alterações cutâneas: manchas hipercrônicas, hipocrônicas e vinhosas, adenomas de face, tumoração, alterações tróficas da pele e anexos.
2.3. Exame de crânio: palpação, percussão, ausculta.

2.4. Exame da coluna: inspeção, movimentação ativa, percussão.

2.5. Exame de ossos e articulações. Alterações tróficas. Pontos dolorosos.

2.6. Aparelho cardio-respiratório.

2.7. Aparelho digestivo.

2.8. Aparelho gêniturinário.

2.9. Pulsos arteriais: carotídeo, radial, femural, pedioso, temporal superficial.

\section{Exame psíquico}

3.1. Estado de consciência: coma, confusão mental. Delírio. Excitação psicomotora.

3.2. Estado mental: Orientação auto e alopsíquica. Atenção. Memória (fixação, conservação, evocação). Afetividade. Associação de idéias. Raciocínio. Alucinação e ilusão.

3.3. Estado emocional: apatia, depressão, ansiedade, hiperemotividade.

O paciente pode estar inconsciente. Poderá estar deitado, no leito de olhos fechados, diferindo do sono por não ser possível despertá-lo, mesmo com estímulos intensos. Neste caso, o paciente está em coma que pode ser superficial ou profundo. A avaliação da profundidade do coma será visto em outro fascículo. $\mathrm{O}$ paciente inconsciente poderá estar acordado, deambulando ou até agitado. Neste caso, poderá não obedecer ordens, não conseguir manter diálogo coerente (confusão mental) ou apresentar alucinações, ilusões ou delírios (de grandeza?). Estes casos são chamados de estados confusionais.

Se o paciente está consciente, avaliaremos a orientação no tempo (dia, mês, ano, idade, etc) e no espaço (endereço onde reside, onde está agora, há quanto tempo, etc).

A atenção e a memória podem ser testadas solicitando ao paciente para repetir seqüências de números ou palavras na ordem direta ou inversa, fazer pequenos cálculos como por exemplo tirar 7 de 100, por 4 a 5 vezes, etc.

Quanto à memória, podemos testar a memória remota, que dificilmente é perdida (onde nasceu, onde morou quando criança, os filhos, etc), a memória recente que, freqüentemente, é comprometida nas síndromes demenciais e pode ser testada, perguntando-se se já almoçou, como veio até o hospital, que dia é hoje, qual a cidade onde está, etc. 
O raciocínio e a associação de idéias podem ser testados, propondo-se pequenos problemas matemáticos ou solução de alguma situação do cotidiano. Pode-se, ainda, pedir para o paciente interpretar pequenas histórias ou provérbios bem conhecidos.

A avaliação do estado emocional é vista em detalhes no curso de Semiologia Psiquiátrica. Devemos assinalar neste ponto do exame a presença de ansiedade excessiva, depressões evidentes ou alteração da afetividade.

\section{Exame neurológico:}

\subsection{Sensibilidade:}

Superficial: táctil, térmica, dolorosa.

Proprioceptiva ou profunda: Cinético-postural.

Vibratória (palestésica).

O exame da sensibilidade sempre é subjetivo, pois depende da informação prestada pelo paciente. É necessário perguntar, antes do início do exame se há alguma região que sente anestesia (ausência de qualquer tipo de sensibilidade) ou parestesia (sensações de formigamento, queimação ou outra sem estímulos para provocá-las). Em seguida, faz-se os estímulos correspondentes:

Dor, de preferência usar um alfinete que provoca dor, mas não penetra a pele. $\mathrm{O}$ examinador testa em si mesmo a força que deve fazer e, depois examina o paciente. Táctil, usa-se um algodão seco, gaze ou um pedaço de lenço de papel. Térmica, usa-se dois tubos de ensaio cheios, um de água fria $\left(+\mathrm{ou}-10^{\circ} \mathrm{C}\right)$ e outro de água quente $\left(+\mathrm{ou}-45^{\circ} \mathrm{C}\right)$, coloca-se de maneira aleatória os tubos, nos locais a serem testados. Os testes devem ser feitos nas regiões suspeitas, comparando-se a sensibilidade dessas regiões com outras, consideradas normais. Uma sistematização interessante pode ser usada: testar os membros iniciando-se dos dedos até a raiz para detectar algum nível em "luva" ou em "bota" de perda das sensibilidades (indicaria polineuropatia periférica) A seguir, testa-se as circunferências dos membros na altura da mão, antebraço, braço, pé, perna e coxa para detectar alguma faixa de perda das sensibilidades (indicaria comprometimento de raízes sensitivas). A seguir, pesquisa-se a sensibilidade do tronco de um lado e do outro, comparando-se áreas homólogas, ao mesmo tempo vai-se caminhando pelo tronco, cranialmente, até a mandíbula (poderia indicar níveis de alteração das sensibilidades sugestivas de patologias medulares). Não esquecer de examinar as regiões ventral e a dorsal.
Na determinação de nível de sensibilidade, com exatidão, pode-se, entrar e sair, com os estímulos correspondentes, nas áreas afetadas, solicitando-se ao paciente dizer o momento que as sensibilidades aumentam (quando sai da área afetada) e diminuem (quando entra na área afetada). Esta manobra poderá ser repetida em casos de dúvidas, várias vezes ou em dias subseqüentes. É necessário fazer-se um mapa das alterações da sensibilidade em um desenho do corpo humano.

Nota: Chama-se Disestesia, quando há uma sensação alterada em relação ao estímulo. Por exemplo: sensação de queimação quando o estímulo é doloroso ou táctil.

A sensibilidade proprioceptiva pode ser pesquisada através de um diapasão (de 128 ou $258 \mathrm{~Hz}$ ), colocando-o nas saliências ósseas: dorso do pé, maléolos, tíbia, rótula, sínfise púbica, cristas ilíacas, falange dos dedos, esterno, olécrono, clavícula, etc. Neste teste, a sensibilidade pode estar diminuindo ou ausente. Deve-se sempre comparar pontos homólogos, partindo de pontos distais para proximais. Para melhor confiabilidade do exame, coloca-se o diapasão ora parado, ora vibrando, solicitando-se ao paciente que faça esta diferença. Explicar e fazê-lo entender que ele deve perceber a vibração (sensibilidade profunda) e não a sensação de algo mais frio encostar na pele (sensação térmica e/ou táctil ).

Outra forma de testar a sensibilidade proprioceptiva é colocar um dos membros numa determinada posição estando o paciente de olhos fechados e solicitar para que coloque o membro homólogo na mesma posição. Isto será feito, corretamente, se houver integridade da sensibilidade profunda. Uma manobra muito usada é balançar os dedos da mão ou do pé, de preferência o primeiro dedo, pegando-o pela bordas laterais e parar com o dedo, ora em flexão, ora em extensão e pedir ao paciente identificar esta posição de olhos fechados (o dedo está para cima ou para baixo?)

\section{2. Motricidade}

\subsubsection{Mão dominante.}

4.2.2. Marcha: com ou sem apoio. Impossibilidade de andar (abasia). Observar os movimentos associados. Andar nos calcanhares, na ponta dos pés, de olhos fechados. Corrida. Andar num pé só. Marcha de olhos fechados, indo e voltando três passos sem virar (Marcha de Babinski -Weill).

As alterações mais comuns da marcha são: marcha espástica (hipertonia em extensão dos membros 
inferiores, uni ou bilateral, mudando o passo com a abdução da coxa sobre a bacia, às vezes, ultrapassando a linha mediana com o membro que está na frente, obtendo-se a marcha "em tesoura") marcha atáxica (ebriosa) marcha talomante (batendo, fortemente, com os calcanhares ao mudar o passo) marcha braquibásica (pequenos passos, arrastando os pés, virando devagar, como se tivesse calçados de chumbo).

4.2.3. Motricidade ativa dos segmentos: Verificar-se há paresias ou plegias.

Pedir para o paciente movimentar todas as articulações. Por exemplo: fletir ou estender os dedos, aduzir e abduzir os dedos, fletir e estender o punho, braço, antebraço, etc. Os movimentos em determinado(s) segmento(s) pode $(\mathrm{m})$ estar ausentes (plegia) ou diminuídos (paresia). De acordo com a região comprometida, teremos os seguintes termos: monoparesia ou monoplegia (diminuição ou ausência de movimento num membro), paraparesia ou paraplegia (diminuição ou ausência de movimento em membros inferiores), diparesia ou diplegia (diminuição ou ausência de movimentos nos membros superiores ou da face), hemiparesia ou hemiplegia (diminuição ou ausência de movimentos na face, membro superior e membro inferior de um lado), hemiparesia desproporcionada (quando um dos três segmentos, citados acima, estiver mais comprometido), hemiparesia ou hemiplegia alterna (diminuição ou ausência de movimentos, envolvendo grupos musculares inervados por um nervo craniano de um lado com hemiparesia ou hemiplegia de membros do lado oposto), quadriparesia ou tetraparesia ou quadriplegia ou tetraplegia (diminuição ou ausência de movimentos dos quatro membros).

4.2.4. Força muscular (note bem, não é a mesma coisa de alteração na motricidade ativa dos segmentos). Provas de contra-resistência e contra a força da gravidade. Classificar a diminuição da força muscular em graus $(0,1,2,3,4$ e 5$)$.

Provas de contra-resistência - colocamos nossa força contra todos os movimentos articulares do paciente e medimos, subjetivamente, sua força, comparando-a com nossos próprios padrões e com a força dos segmentos contralaterais homólogos. Exemplos: pedimos para o paciente abduzir seus braços contra uma resistência que o examinador faz, segurando os braços aduzidos contra o tronco, pedimos para o paciente apertar nossas mãos, as duas ao mesmo tempo, comparando a força das mãos, etc.
Provas contra a força da gravidade - colocamos os membros superiores estendidos para frente, em ângulo de $90^{\circ}$ com o tronco, com as mãos supinadas e os dedos abduzidos e estendidos. Nessa posição, o paciente deve permanecer por mais de um minuto. Havendo alterações nas posições dos braços, mesmo que seja apenas a adução dos dedos ou a tendência à pronação das mãos, há diminuição da força muscular, principalmente se esses achados forem unilaterais. Esta prova deverá ser feita, preferentemente, com o paciente sentado. Se estiver deitado, os braços deverão ficar num ângulo $<90^{\circ}$, em relação ao tronco, para a força da gravidade poder atuar sobre os mesmos. A seguir, examinamos os membros inferiores com o paciente deitado em supino. Pedimos para colocar os membros inferiores elevados com flexão da coxa sobre a bacia e da perna sobre a coxa em ângulos $>$ de $90^{\circ}$ (prova de manobra obstétrica ou de Mingazzini). A incapacidade de manter essa posição, por mais de um minuto, indica diminuição da força muscular dos membros inferiores que pode ser uni ou bilateral. Virando-se o paciente de bruços pedimos agora para fletir a perna sobre a coxa, mantendo em ângulo $>90^{\circ}$, entre os segmentos (prova de Barré).

4.2.5. Trofismo Muscular. Circunferência dos braços, antebraços, coxas e pernas. Atrofias ou hipotrofias musculares: primária ou miogênica, desuso, parietal. Hipertrofia e pseudo-hipertrofia.

Examina-se o trofismo muscular pela inspeção, olhar locais de maior comprometimento como os interósseos, adutor do polegar, deltóide, cintura escapular, panturrilhas, coxas, etc. Quando houver dúvidas quanto à presença de assimetria, podemos medir com fita métrica os perímetros das coxas, pernas, braços e antebraços em lugares, previamente, marcados e simétricos. O trofismo muscular poderá estar aumentado em algumas doenças raras. $\mathrm{O}$ aumento do volume do músculo, no entanto, pode se dar pelo aumento de tecido fibroso conjuntivo (pseudo-hipertrofia).

4.2.6. Tono muscular: Consistência muscular. Palpação. Passividade: balanço do segmento distal, através do proximal. Estensibilidade. Hipotonia e Hipertonia. (piramidal e extrapiramidal).

Examina-se o tono muscular através da: a) palpação - observar a flacidez ou o enrijecimento anormal de cada músculo; b) balanceio do segmento distal, através do proximal — balança-se as duas mãos, solicitando do paciente que as relaxe o mais possível, 
através do movimento de vai e vem rápido do antebraço. A amplitude do movimento das mãos será proporcional ao grau de hipotonia ou hipertonia. Essa manobra deve ser feita, também, nos pés e será mais sensível, se houver assimetria do tono muscular. c) Estende-se o mais possível alguns grupos musculares, se, na flexão do antebraço sobre o braço, o punho alcançar o ombro há hipotonia, se, na flexão da perna sobre a coxa, o calcanhar alcançar a nádega, há hipotonia. Essa manobra poderá ser feita em todas as articulações, punhos, pés, ombros, coluna, etc.

Hipertonia piramidal: estando o segmento estendido, na tentativa de fleti-lo (solicitando do paciente que fique relaxado) há uma resistência inicial e, vencida esta resistência inicial o movimento fica fácil, quase espontâneo até a flexão total do mesmo (sinal de canivete).

Hipertonia extrapiramidal: estando o segmento fletido ou estendido, ao estendê-lo ou fleti-lo há resistências periódicas, como se fosse uma roda denteada. Este tipo de hipertonia poderá ser detectada supinando e pronando as mãos do paciente, ficando este, passivo em relação ao movimento imprimido pelo examinador.

4.2.7. Movimentos involuntários anormais. Localização. Frequiência. Regularidade. Amplitude. Relação com os movimentos voluntários e emoções. Tipo: coréia, atetose, balismo, tremores, mioclonias, distonia, fasciculação, tiques

O exame é feito pela inspeção. Coloca-se o paciente sentado, com os braços estendidos para frente, mãos em pronação e dedos em adução. Pede-se ao mesmo tempo para o paciente colocar a língua para fora da boca. Nesta posição, podem surgir movimentos involuntários como tremores, asterixe, coréia, atetose, mioclonias, etc. Depois, pede-se ao paciente para fletir o antebraço e abduzir os braços, com as mãos em frente do rosto e os dedos indicadores estendidos, estando os demais dedos fletidos. Os indicadores devem estar próximos, um em frente ao outro, sem se tocarem. Nesta posição, observa-se melhor os tremores posturais e o bater de asa. "Bater de asa" caracteriza-se pelo movimento involuntário de abaixar e elevar os cotovelos, mantida a posição descrita acima. Estes e outros tipos de movimentos involuntários anormais como os tiques, balismo, distonias, fasciculação, etc. serão descritos em doenças específicas.

\subsection{Coordenação}

4.3.1. Equilíbrio estático: em pé. De olhos abertos e fechados.
O paciente deve ficar em pé, com os pés encostados um no outro e os braços soltos ao longo do corpo. Astasia é a incapacidade de manter-se em pé. De início, o paciente fica de olhos abertos, fixados num ponto distante, na horizontal. A seguir, pede-se para fechar os olhos. Se o desequilíbrio surgir ou aumentar de olhos fechados, chamamos de Sinal de Romberg positivo (indica, na maioria das vezes, comprometimento de sensibilidade proprioceptiva). A prova do equilíbrio pode ser sensibilizada, empurrando-se, subitamente, o paciente para frente, para traz ou para os lados ou, então, pedindo para o paciente colocar o calcanhar de um pé em frente dos dedos do outro, ombros ficando em linha reta.

4.3.2. Taxia cinética. Prova index-nariz ou index-orelha. Preensão do copo. Prova dos riscos horizontais de Babinski, Rebound (prova de Steward-Holmes)

Na prova index-nariz, e index-orelha solicita-se ao paciente para estender e abduzir os braços e, a seguir, colocar os dedos indicadores no nariz ou na orelha, repetidamente. A prova poderá ser realizada com movimentos simétricos e ao mesmo tempo ou alternadamente, colocando-se primeiro o índex direito no nariz (ou orelha) voltando a estender o braço direito e, a seguir, fletir o braço esquerdo, colocando o índex esquerdo no nariz (ou orelha) repetindo-se essa sequiência várias vezes, de olhos abertos e, a seguir de olhos fechados. Durante o movimento, observamos a harmonia, a medida e o aparecimento de tremores. Alterações:

a - Na harmonia do movimento com fases de movimento mais rápidos e mais lentos, mais para o alto ou mais para baixo.

b - Na medida do movimento com interrupção, antes do alvo (nariz ou orelha) ou a ultrapassagem do alvo (dismetria) e

c - Tremor que se acentua quando o índex está parado, próximo do alvo (tremor de intensão).

A prova do calcanhar-joelho testa a coordenação dos membros inferiores. Deve ser feita com o paciente, em decúbito dorsal, solicitando que coloque um dos calcanhares no joelho oposto e, a seguir, deslize o calcanhar encostado na região tibial da perna, até a ponta dos pododáctilos. Este movimento deve ser feito alternado, ora com um membros, ora com o outro, com o paciente olhando os movimentos e, a seguir, de olhos fechados. As alterações citadas nas provas index-nariz e index-orelha deverão ser observadas nesta. Quando 
as alterações se acentuam, após o fechamento dos olhos, há comprometimento da sensibilidade propioceptiva.

Outras provas, poderão ser feitas para avaliação da coordenação muscular, por exemplo, pegar um copo cheio de água e levá-lo à boca, vestir-se, abotoar as roupas, fazer riscos horizontais, limitados por 2 traços verticais, escrita, etc.

Diadococinesia é a capacidade de inverter, rapidamente, a direção de um movimento. As duas provas mais utilizadas para avaliação da diadococinesia são: a supinação-pronação da mão (movimentos rápidos, alternados, batendo ora com a palma, ora com o dorso da mão no divã ou no próprio joelho) e a do rebote ("rebound") solicitando-se do paciente para fazer força de flexão do antebraço sobre o braço com o examinador segurando o antebraço pelo punho e, subitamente, o examinador solta o antebraço; reflexivamente, o paciente inverte o sentido da força que está fazendo, surgindo, inclusive uma pequena extensão do antebraço. Estas provas alteradas indicam que há disdiadococinesia (incoordenação de origem cerebelar).

4.3.3. Nistagmo: horizontal, vertical, rotatório, misto. Nistagmo central e periférico.

Nistagmo é melhor estudado na semiologia Otoneurológica. O clínico geral deve, de rotina pesquisar o nistagmo, solicitando do paciente para olhar para um dos lados, depois, para o outro lado, para cima e para baixo. Nistagmo uniocular é sempre de origem central. Nistagmo multidirecional, em geral, é de origem central. Movimentos oculares incoordenados, ora mais rápidos ora mais lentos, mas sem caracterizar um nistagmo típico, é de origem cerebelar.

4.3.4. Habilidade: Escrever. Vestir-se. Abotoar-se.

4. 4. Reflexos: Obtenção. Manobras de facilitação. Nível de integração. Grau de respostas (0: ausente, 1: hipoativo, 2: normal, 3: hiperativo, 4: policinético).

4.4.1. Reflexos profundos: Orbicular das pálpebras (ponte). Orbicular dos lábios (ponte). Mandibular (ponte). Peitoral (C8- T2). Bicipital (C5 -6). Tricipital (C6 - 8). Estilorradial - resposta proximal (C5 - 6) distal (C7 - 8). Flexor dos dedos: (C7-8-T1). Costo-abdominal (T6-9). Médio-púbico (T6-12). Adutor da coxa (L2-4). Patelar (L2 -4) Aquileu (S1-2). Flexor dos dedos dos pés (S1-2). Aumento da área reflexógena dos reflexos profundos. Clono de pé, rotuliano, de mandíbula. Tríplice flexão.

Toda manobra para obtenção dos reflexos profundos ou miotáticos tem, como objetivo único, o estiramento rápido do músculo ou melhor dos fusos mioneurais. Lembrar-se sempre desta afirmação, toda vez que estiver aprendendo a evocação de um reflexo miotático. Os reflexos profundos são obtidos batendose com um martelo apropriado no tendão do músculo, sua distensão rápida leva à contração reflexa e ao relaxamento simultâneo dos músculos antagonistas. Algumas manobras facilitam o exame:

a - o estado do músculo, deve-se mantê-lo não muito estirado nem muito frouxo, deve-se procurar um estado intermediário, distendendo-o, passivamente, com auxílio da mão esquerda (se o examinador for destro). Por exemplo: no caso do reflexo aquileano, flete-se dorsalmente o pé, mantendo-o numa posição intermediária entre a flexão e extensão.

b - a pesquisa de reflexos homólogos deve ser feita com o mesmo procedimento, de preferência em seqüência e com os músculos em igual grau de contração. Só assim terá valor uma assimetria.

c - Se um reflexo não é obtido, solicita-se do paciente para contrair, voluntariamente, outros segmentos do corpo, como por exemplo, ao se pesquisar os reflexos dos membros inferiores o paciente segura uma mão na outra e faz força com os membros superiores.

Reflexos axiais da face: Orbicular das pálpebras, percutir a região glabelar com interposição do dedo indicador da outra mão; resposta, contração dos músculos orbiculares das pálpebras, visível pelo piscar bilateral. Orbicular da boca, percutir com interposição do dedo a região supra ou infrabucal, procurando distender o músculo orbicular da boca, ou seja no caso do dedo estar na região supra bucal, bater com o martelo de baixo, para cima; resposta de mímica parecendo com assobio ou beijo. Masseterino, bater com o martelo no queixo de cima para baixo, com interposição de dedo distendendo, subitamente, os m. masseteres, estando a boca relaxada e semi-aberta; resposta, fechamento da boca.

Reflexos dos membros superiores: Peitoral, percutir o tendão do músculo peitoral na sua inserção no úmero, ou seja na borda anterior da axila com interposição do dedo, estando o braço um pouco abduzido (cerca de $20^{\circ}$ ) e o antebraço fletido; resposta, adução do braço. Bicipital, percutir o tendão do bíceps na sua 
inserção na região interna do cotovelo com interposição do dedo (fossa intercubital) e com o antebraço fletido em $90^{\circ}$ em relação ao braço. Se o paciente estiver sentado, o antebraço e as mãos ficarão apoiadas nas coxas homolaterais, com os membros superiores bem relaxados. Se o paciente estiver deitado, apoia-se as mãos e a região distal do antebraço sobre o abdome, estando o antebraço fletido num ângulo $90^{\circ} \mathrm{em}$ relação ao braço e o braço, levemente abduzido. Resposta, contração do bíceps com flexão do antebraço. Estilorradial, a posição do antebraço é a mesma do reflexo anterior, percutir a cabeça distal do radio ou seja na inserção do tendão do músculo estilorradial no radio com ou sem interposição de dedo. Resposta, podemos observar contração do músculo estilorradial com flexão do cotovelo e tendência à pronação da mão e do profundo comum dos dedos com flexão dos dedos da mão. Tricipital, percutir o tendão do m. triceps no olécrono, sem interposição do dedo com o braço fletido e, levemente, abduzido (mesma posição para os reflexos supracitados). O paciente estando deitado, o examinador eleva um pouco o cotovelo da cama para facilitar a percussão. Se o paciente estiver sentado o examinador eleva o cotovelo de forma a manter o braço na mesma linha do corpo com o antebraço solto, fazendo um ângulo de $90^{\circ}$ com o braço. Resposta, extensão do antebraço. Flexor dos dedos, com as mãos em supinação e os dedos semifletidos, coloca-se o dedo indicador do examinador, transversalmente na palma da mão do paciente e percute-se. Resposta, flexão dos dedos. Podemos usar duas outras manobras. (Troemer e Hoffmann), para obtenção deste mesmo reflexo.

Reflexos dos membros inferiores. Médio-púbico percutir a sínfise púbica, com o paciente deitado e com interposição do dedo e os membros inferiores estendidos, abduzidos num ângulo de + ou $-20^{\circ}$. Resposta superior, contração do musculatura abdominal, resposta inferior, adução e rotação interna dos membros inferiores. Adutor das coxas, percussão dos tendões dos adutores, na inserção, na região interna do fêmur, com interposição do dedo. Usualmente, percute-se a região interna da coxa, logo acima do final do fêmur com as coxas, levemente, abduzidas e o paciente sentado ou deitado. Resposta, adução das coxas. Patelar, percute-se o tendão do músculo quadriceps entre a rótula e a cabeça da tíbia, com o paciente sentado, sem interposição do dedo. Se o paciente estiver deitado, eleva-se as duas coxas com o antebraço esquerdo sob os joelhos, pedindo ao paciente para man- ter os membros inferiores relaxados, ou seja, os calcanhares ficarão apoiados na cama, (mantendo-se um .ângulo de + ou $-120^{\circ}$, na articulação do joelho). Resposta, extensão da perna sobre a coxa. Aquileano com o paciente sentado, eleva-se um pouco o pé para manter-se em ângulo de + ou $-90^{\circ}$ entre a perna e o pé e percute-se o tendão na sua inserção no calcâneo. Se o paciente estiver deitado coloca-se o pé esquerdo, com pequena flexão deste membro, sobre a perna direita estendida e fletindo-se, dorsalmente, o pé com a mão esquerda, percutir o tendão de Aquiles. Resposta, contração do músculo triceps crural com extensão do pé. A seguir, pesquisa-se o reflexo contralateral, invertendo-se a posição dos membros inferiores. Flexor dos dedos dos pés, com o paciente deitado e o pé ligeiramente dorsifletido, percutir a base dos artelhos, sem interposição do dedo. Resposta, flexão dos dedos do pé.

Os reflexos miotáticos podem estar ausentes, hipoativos, hiperativos e policinéticos (seguidas contrações musculares, após uma percussão). Quando os reflexos miotáticos estão hiperativos pode surgir:

a - aumento da área reflexógena; às vezes, obtém-se o reflexo bicipital ao percutir o tendão do músculo peitoral,

b - tríplice flexão que é a contração reflexa dos músculos flexores dos membros inferiores, provocados por estímulos mínimos ou espontaneamente (flexão da coxa sobre a bacia, da perna sobre a coxa e do pé sobre a perna) e,

c - clono que são abalos rítmicos repetitivos de grupos musculares que surgem espontaneamente ou provocados. Provoca-se o clono do pé, com a súbita flexão dorsal do pé, estando o paciente deitado e o membro inferior estendido. Provoca-se o clono da rótula com o paciente deitado e o membro inferior, ligeiramente, fletido. Segurando-se a rótula pela sua borda superior, subitamente abaixá-la, mantendo-a nesta posição. Estes achados (reflexo policinético, tríplice flexão e clono) indicam lesão do neurônio motor superior.

4.4.2. Reflexos superficiais: cutâneos abdominais: superior (T7-9), médio (T9-11), inferior (T11-12). Cremastéricos (L1-2). Cutâneo-plantar (L5-S1-2). Anal. Palmo-mentual (Marinesco). Sinal de Babinski e equivalentes (Oppennheim, Gordon, Chaddoc, Schaeffer).

Nos reflexos superficiais (cutâneos e mucosos) o estímulo provocador do reflexo é superficial, feito, em 
geral, com um estilete de ponta romba (palito de fósforo) e a resposta é a contração de um grupo muscular.

Reflexos cutâneos. Cutâneo abdominal, estimulação com uma ponta romba a pele da região abdominal dos flancos para a cicatriz umbilical na região da inervação das raízes T7-T9, T9-T10, T11-T12, estando o paciente deitado. Resposta, contração da musculatura abdominal com desvio da cicatriz umbilical para o lado estimulado. Cremastéricos, estimulação da pele da face interna da coxa com o paciente deitado. Resposta, contração da musculatura cremastérica homolateral com elevação de testículo. Cutâneo e plantar, estimulação da planta dos pés, do calcanhar em direção aos dedos, pela borda lateral do pé, com o paciente deitado. Resposta, flexão dos podadáctilos. Palmomentual, estimulação cutânea da palma da mão, na região mediana, do punho em direção aos dedos. Resposta, contração da musculatura mentoniana homolateral.

Reflexos mucosas. Anal, estímulo da mucosa anal, resposta, contração do esfíncter anal. Córneo palpebral, ver V nervo craniano.

Os reflexos superficiais nunca estão exacerbados ou hiperativos. Podem estar hipoativos ou ausentes (por exemplo, na lesão do feixe piramidal). Neste caso, o reflexo cutâneo plantar pode estar ausente e, no seu lugar, surgir o sinal de Babinski, ou seja a extensão ampla e majestosa do hálux e abdução dos demais pododáctilos. Tal resposta pode ser obtida, apertando com a mão a musculatura da panturrilha (sinal de Gordon), apertando com os dedos, polegar e indicador o tendão de Aquiles (sinal de Schaeffer), deslizando com força os dedos do examinador de cima para baixo na crista da tíbia (Sinal de Oppennheim) ou deslizando uma ponta romba na região lateral do pé, do maléolo externo até o $5^{\circ}$ pododáctilo (Sinal de Chaddoc).

\subsection{Nervos Cranianos:}

4.5.1. Nervo Olfativo: Provas olfativas. Anosmia. Alucinações.

O olfato é pesquisado com auxílio de recipientes pequenos, contendo café, baunilha, limão, canela ou outros odores suaves. Aproxima-se um dos recipientes de uma das narinas (antes, tapa-se a narina oposta) e depois, da outra narina. Repete-se a operação, algumas vezes, até ter certeza do olfato de ambas as narinas do paciente. Anosmia é o termo usado para a perda do olfato. Paraosmia é o termo usado para a percepção alterada do olfato (dizer que a baunilha tem cheiro desagradável, por exemplo).
4.5.2. Nervo Óptico: Acuidade visual. Campo visual: escotoma, hemianopsia (homônima, hecteronima), quadrantopsia. Fundo de olho. Atrofia e edema de papila.

Examina-se a acuidade visual colocando-se em frente do paciente, a uma distância proporcional ao tamanho da letra, algo escrito e pede-se para que ele identifique palavras, letras e números, ora com um olho, ora com o outro. É importante não apertar o olho que está sendo tapado para não prejudicar a visão deste olho, após destapá-lo. É necessário verificar a visão para perto e para longe. O campo visual está alterado nas lesões quiasmáticas e retroquiasmáticas e pode ser, avaliado, solicitando-se do paciente que olhe, fixamente, na testa do examinador, estando este bem à frente do examinado. A seguir, o examinador desloca o dedo indicador de ambas as mãos, nos vários pontos do campo visual do examinado. O examinador olha fixamente no olho do examinado para ter certeza do mesmo não desviar o olho da testa. As hemianopsias ou quadrantopsias são detectadas com certa facilidade, através desta prova. Chama-se hemianopsia a perda total ou quase total da metade do campo visual. Quando as duas metades são do mesmo lado do campo visual ou seja, campo nasal de um olho e o temporal do outro olho, a hemianopsia é chamada de homônima. Quando houver comprometimento dos campos bitemporais ou binasais a hemianopsia é chamada de heterônima. A perda de 1/4 do campo visual é chamada de quadrantopsia.

Os escotomas centrais e amaurose surgem em lesões pré-quiasmáticas e são percebidas quando o paciente queixa-se de cegueira deste olho. Na amaurose, a perda visual é total, enquanto que no escotoma central há conservação do campo periférico. Existem situações como, por exemplo, na hipertensão intracraniana que a perda do campo visual é periférica e o examinador poderá demonstrar uma visão tubular.

O exame do fundo de olho será visto na semiologia oftalmológica e consta do exame, através do oftalmoscópio.

4.5.3. Nervos oculomotores. Movimentação ativa dos globos oculares. Diplopia. Olhar conjugado lateral, vertical superior e vertical inferior. Vergência. Paralisia isolada dos nervos oculomotores. Fenda palpebral. Pupilas. Reflexos pupilares: fotomotor, consensual, de convergência, de acomodação.

Examina-se motilidade ocular solicitando-se do paciente que olhe de um lado, do outro, para cima e 
para baixo, estando sua cabeça fixa, dirigida para frente. Deve-se, também, testar a motilidade ocular em direção intermediária àquelas, ou seja, obliquamente para cima e para fora, para cima e para dentro, etc. A seguir, pede-se para olhar para um dedo, colocado próximo aos olhos, na linha mediana, para testar a capacidade de convergência ocular. Nestes exames, poderão surgir anormalidades:

a - diplopia (que desaparece se um dos olhos está fechado), indicando que o movimento de ambos os olhos não foram simétricos.

b - a excursão de um ou de ambos os olhos não é total para uma ou mais direção testada.

Quando um olho não excursiona, totalmente para fora, o nervo abducente (VI) está lesado. Quando o olho tem várias limitações, exceto para a sua abdução completa, o nervo lesado é o motor ocular comum (III). Neste caso, em repouso, o olho comprometido fica em abdução e em midríase.

Quando os dois olhos não excursionam, normalmente, para uma direção o distúrbio é quase sempre no tronco cerebral ou em região mais rostral. Podemos ter paralisia (ou paresia) do olhar vertical (de ambos os olhos) para cima, para baixo, ou paralisia (ou paresia) do olhar horizontal para um dos lados, ou incapacidade de convergi-los. Cada uma destas deficiências corresponderá a topografias específicas.

Em seguida, examina-se a fenda palpebral. Poderá estar mais aberta nas exoftalmias, fechada parcialmente (lesão do simpático cervical) ou totalmente (lesão do III nervo craniano).

As pupilas são examinados pela inspeção, observando-se simetrias e regularidade das bordas pupilares. Midríase, surge na lesão do III nervo e miose, na lesão do sistema nervoso simpático cervical. As reações pupilares à luz devem ser testadas, solicitando-se ao paciente olhar distante, para um ponto da parede oposta e fazendo um feixe de luz (lanterna de feixe estreito) penetrar na pupila examinada, obliquamente, colocando-se a lanterna lateralmente ao eixo do olho. Haverá miose. Neste olho (reflexo fotomotor direto) e no olho oposto (reflexo consensual). As pupilas, também, ficam mioticas ao se aproximar um objeto dos olhos. O examinador coloca seu dedo bem na frente dos olhos do paciente à pelo menos 1 metro e vai aproximando o dedo do olho, à medida que isto é feito os olhos vão se convergindo e as pupilas vão ficando mióticas (reflexo de acomodação ou convergência visual).
4.5.4. Trigêmio: sensibilidade superficial da face (pele e mucosas). Motricidade: masseter, temporal, pterigodeos, desvio da mandíbula. Reflexos corneo-palpebral, estornutatório e mandibular.

A sensibilidade superficial da face é testada como foi explicado no exame de sensibilidade. Não esquecer que o trigêmio, também, leva à sensibilidade da boca, língua até os pilares amigdalianos. A sensibilidade profunda vibratória da face não é pesquisada, pois este estímulo entrará no SNC, através do VIII nervo (acústico). A mastigação é testada, solicitando-se ao paciente para prender um abaixador de língua entre os dentes molares de um lado e do outro. No lado parético, o examinador retirará o abaixador de língua com maior facilidade. Ao abrir a boca, o examinador observará desvio de mandíbula. Quando um dos nervos trigêmios está deficiente, a mandíbula se desviará para este lado. $\mathrm{O}$ reflexo corneo-palpebral (referência é dada pelo $\mathrm{V}$ nervo) será examinado tocando-se o limbo corneano (parte colorida do globo ocular) com um filete de algodão. A resposta (fechamento das pálpebras) é função do nervo facial; para facilitar esta pesquisa, solicita-se ao paciente para olhar para cima e para o lado oposto ao olho examinado. O reflexo esternutatório é pesquisado, colocando-se um filete de algodão nas narinas de um lado e, a seguir ao outro, o que provocará fuga e desconforto para o paciente, se a sensibilidade das cavidades nasais ( $\mathrm{V}$ nervo) estiver preservada. O reflexo mandibular ou masseterino foi pesquisado no capítulo de reflexos profundos.

4.5.5. Facial: Inspeção. Motricidade mímica da face, sensibilidade gustativa dos $2 / 3$ anteriores da língua. Reflexos: nasopalpebral, córneo-palpebral, oroorbicular, palmomentual. Sinal de Chvostek. Sinal de Bell.

Pela inspecção, pode-se notar assimetria facial, com apagamento do sulco naso-geniano, lagoftalmo, desaparecimento das rugas e vincos faciais do lado lesado. A mímica facial é testada, solicitando-se ao paciente para fechar os olhos, enrugar a testa, assobiar, sorrir e, com a boca aberta, mostrar os dentes (contrai o m. plastina). Além da inervação dos músculos da mímica facial, o VII nervo recolhe a sensação gustativa dos $2 / 3$ anteriores da língua. Testa-se a gustação, colocando-se num tubo capilar ou num cotonete, soluções salgada, doce, amarga e azeda. Toca-se, então, em um dos lados da língua, na sua região papilar e espera-se alguns segundos, até o paciente perceber o gosto, ficando de boca aberta. A seguir, o paciente lava a boca com bochechos de água e, novamente, expõe 
a língua, que será estimulada, do outro lado, com outra solução. Repete-se o procedimento até o examinador ter certeza da presença ou não da gustação na língua.

Os reflexos nos quais o nervo facial toma parte, como efetor, são: nasopalpebral (ver reflexos profundos) córneo-palpebral (ver V nervo craniano) palmomentual (ver reflexos cutâneos). O sinal de Chvostek que pode sugerir hipocalcemia é pesquisado, percutindo-se as glândulas parótidas. Em caso positivo, haverá desvio de rima bucal para o lado estimulado.

Quando há paralisia do nervo facial de um lado, haverá impossibilidade do fechamento da pálpebra, pois este nervo supre o músculo orbicular das pálpebras. Na tentativa de fechar a pálpebra, esta permanece aberta e o olho roda, reflexivamente, para cima (Sinal de Bell). O comprometimento de toda musculatura mímica unilateral surge na chamada paralisia facial periférica, ou seja quando a lesão está no núcleo ou abaixo dele. Nas lesões supranucleares, haverá comprometimento da musculatura mímica do andar inferior da face (paralisia facial central).

4.5.6. Auditivo: ramo coclear. Alteração da acuidade auditiva, prova de Weber. Surdez de condução e percepção. Ramo vestibular: tonturas, vertigens, acúfenos, nistagmo (espontâneo e provocado).

A função auditiva pode ser testada, aproximando-se de cada um dos ouvidos, alternadamente objetos que fazem ruídos baixos como, por exemplo, relógio, diapasão. A acuidade auditiva poderá ser avaliada, comparando-se a audição do examinador com a do paciente. Há necessidade de sabermos se uma hipoacusia (diminuição da audição) é de condução ou de percepção. Na surdez de condução, há diminuição da audição aérea, enquanto que na de percepção, há diminuição da audição aérea e óssea. Testa-se a audição óssea colocando-se o cabo de um diapasão, vibrando nas apófises mastoídeas ou no alto da cabeça. Prova de Weber coloca-se o diapasão vibrando no alto da cabeça, se o paciente acusar que ouve o som do lado direito, isto pode indicar duas coisas: a) surdez de percepção, à esquerda ou b) surdez de condução, à direita. O teste do diapasão, colocado perto dos ouvidos, determinará se a opção a ou se a opção b está correta. Ouvido esquerdo surdo, opção a; ouvido direito surdo, opção b.

$\mathrm{Na}$ alteração vestibular o paciente, em geral, queixa-se de tonturas rotatórias (vertigens) e desequilíbrio muitas vezes acompanhadas por zumbido, estalos ou outros ruídos na cabeça (acúfenos). Algumas provas estão alteradas nas lesões do VIII nervo (parte vestibular). Quando o paciente anda, tende a desviar-se sempre para o mesmo lado (ao contrário da lesão cerebelar, que pode desviar para qualquer lado). Quando se pede para fazer a marcha de Babinski-Weill (ver exame de marcha) o paciente desvia-se a cada segmento andado, desenhando no chão como estrela (marcha em estrela). Quando se testa o equilíbrio, o paciente tende a cair sempre para o mesmo lado. Os labirintos, também, coordenam os movimentos oculares, surgindo o nistagmo, quando lesados. Testa-se a presença de nistagmo solicitando-se ao paciente para manter o olhar nas extremidades da fenda palpebral por alguns segundos. O nistagmo pode ser unidirecional, multidirecional, horizontal, vertical, rotatório ou monocular (ver exame da coordenação).

A semiologia mais detalhada do VIII nervo deverá ser demonstrada na Neurootologia.

4.5.7. Glossofaríngeo e Vago: Disfagia. Sensibilidade gustativa do 1/3 posterior da língua. Desvios do palato e úvula. Sensibilidade da faringe. Sinal da cortina. Reflexo do vômito.

Os nervos glossofaríngeo e vago podem ser examinados juntos. Os pacientes, com lesões nestes nervos, queixam-se, em geral, de dificuldade para deglutir (disfagia), principalmente, para alimentos líquidos com engasgos e/ou refluxo para as cavidades nasais e dificuldade para falar (disartria), com voz bitonal ou anasalada. $\mathrm{O}$ exame de sensibilidade gustativa foi explicado no VII nervo craniano. O exame da motricidade do palato mole e da úvula é feito, solicitando-se para o paciente abrir a boca, estando sentado, e depois de visualizar as partes a serem examinadas, pede-se para o mesmo falar Ah! ou Eh! e manter esta vocalização por alguns segundos. Observa-se, neste momento, a contração da musculatura do palato. Quando os nervos de um lado estão paralisados, somente o palato do lado oposto subirá, desviando a úvula para este lado, do lado lesado o palato ficará hipotônico e abaixado, (sinal da cortina). Se os nervos dos dois lados estiverem lesados, o som sairá anasalado, a úvula e o palato não subirão.

A sensibilidade da faringe é testada com um abaixador de língua, tocando os pilares amigdalianos de um lado, perguntando-se ao paciente se sentiu e, depois do outro, repetindo-se a mesma pergunta. Muitas vezes, essa pergunta é desnecessária, pois surge o reflexo do vômito que confirmará a presença da sensibilidade. Outros tipos de sensibilidade como a dolorosa e a térmica não são, de rotina, examinados nesta região. 
4.5.8. Acessório: bulbar e espinhal. Inervação das cordas vocais. Inervação do trapézio e esternoclidomastóideo.

O nervo acessório bulbar inerva, juntamente, com um ramo do nervo vago as cordas vocais. Juntos formam o nervo recorrente laríngeo. Na lesão unilateral deste nervo, surge alteração na tonalidade da voz, voz bitonal. As cordas vocais podem ser examinadas, através do exame otorrinolaringológico.

A porção espinhal do XI nervo craniano inerva os músculos trapézio e esternoclidomastoídeo. Quando há deficiência bilateral, há dificuldade para manter o segmento cefálico ereto (se o paciente estiver sentado) ou levantá-lo do leito (se estiver deitado). Se a dificuldade for unilateral, haverá tendência de desvio do segmento cefálico para o lado comprometido. A força do trapézio é avaliada, solicitando-se ao paciente para elevar os ombros contra a resistência do examinador. Este comparará a força de um com a do outro lado. O esternoclidomastóideo é testado solicitando-se ao paciente para rodar a cabeça num eixo vertical para a direita, com o examinador contrapondo resistência no rosto, isto exigirá contração do músculo do lado esquerdo. A rotação para o lado oposto testará o músculo do lado direito.

4.5.9. Hipoglosso: aspecto, atrofias e fasciculações da língua. Movimentação dentro e fora da boca.

A inervação motora da lingua é testada observando o trofismo e os desvios da língua. Quando a língua é colocada para fora da boca, ela desviará para o lado paralisado. Quando a língua é puxada para o fundo da boca, ela é desviada para o lado são. A seguir, solicita-se ao paciente para, com a língua fora da boca, dobrá-la para cima, para baixo, para os lados. Na paralisia da hemilíngua direita o paciente não conseguirá dobrá-la para o lado esquerdo. Quando houver deficiência bilateral, haverá paresia ou plegia de todos os movimentos.

\subsection{Sinais Meníngeos}

Sinais de Kernig, Brudzinski e Laségue. Características dos sinais meníngeos em lactentes.

Rigidez nucal é testada fletindo, subitamente, o segmento cefálico, estando o paciente, deitado em decúbito dorsal. Se o teste for positivo, é necessário verificar se há resistência à lateralização do segmento cefálico, em caso positivo, a rigidez nucal poderá ser con- sequiência de distúrbio da coluna cervical, ao invés de irritação meníngea. Mantendo-se a flexão do pescoço, por alguns segundos, na posição máxima, poderá haver flexão dos membros inferiores (sinal de Brudzinski). Fletindo-se os membros inferiores nas articulações coxo-fêmurais e nos joelhos mantendo-se ângulo de $90^{\circ}$ entre os segmentos, haverá resistência na extensão passiva, feita pelo examinador, dos joelhos (sinal de Kernig).

Nos lactentes, os sinais meníngeos são, em geral, negativos, mesmo na presença de meningite. Nesta faixa etária, a criança fica irritada, com abalamento da fontanela e posição em opistótono, quando há meningismo.

\subsection{Distúrbios da Linguagem:}

4.7.1. Linguagem falada. Dislalia. Disartria. Mutismo. Disfasias. Jargonofasia.

4.7.2. Linguagem escrita: grafia e leitura.

\subsubsection{Cálculo numérico.}

A semiologia da linguagem é muito complexa. Existem especialistas que se dedicam a esta importante função. Veremos aqui apenas algumas definições, importantes para o dia-a-dia de médicos não especialistas. A linguagem falada é avaliada durante todo exame neurológico. $\mathrm{O}$ aparecimento de tartamudez ou troca de consoantes é chamada de dislalia, não havendo substrato anatômico que explique estas deficiências de linguagem.

Disartria é a alteração da fala, conseqüente a lesão do aparelho fonador, dos nervos que participam de fonação (IX, X, XI, XII) do sistema cerebelar ou extrapiramidal. Na disartria, a fala pode ser explosiva ou monótona (s. cerebelar); baixa, mal articulada e monótona (s. parkinsoniana), anasalada (IX e X nervos cranianos), bitonal (XI nervo craniano bulbar), etc.

No mutismo, o paciente não tem iniciativa de falar, embora esteja consciente e, às vezes, compreendendo ordens. Surge em pacientes com distúrbios psíquicos ou com lesão unilaterais paramedianas frontais.

Disfasia é a incapacidade do paciente em expressar, através da fala, os seus pensamentos, embora possa fazê-lo através de gestos. Aparecem quando são lesados alguns locais específicos do córtex cerebral (centros da fala). Na lesão da área de Brocca, o pa- 
ciente percebe sua deficiência, se angustia na tentativa de falar, mas não consegue. Poderíamos comparar com a lesão da área motora, o paciente quer mover o braço, mas não consegue. Às vezes, esta afasia vem acompanhada da incapacidade de escrever e outras vezes, não. Na lesão da região temporoparietal do hemisfério dominante, pode surgir a afasia (ou disfasia) amnéstica ou nominativa, na qual o paciente não consegue dar nomes a objetos mostrados mas, no decorrer de uma conversa fala o nome deste objeto, sem dificuldade. Na jargonofasia, o paciente fala uma linguagem, totalmente, estranha e incompreensível e não reconhece sua deficiência (anosognosia).

Nas lesões de determinadas regiões corticais do hemisfério dominante podem surgir incapacidade para a linguagem escrita, leitura e para cálculos matemáticos.

\subsection{Distúrbios da Praxia}

A praxia é a incapacidade de realizar sequiências de atos motores complexos com certa finalidade. Pode-se testar, solicitando-se do paciente que faça continência, dê um laço no cordão do sapato, enfie linha numa agulha, penteie o cabelo, vista-se, desenhe algumas figuras num papel (casa, relógio, etc), dirija um veículo, etc. Estes testes poderão ser feitos, solicitando-se que o paciente apenas faça os movimentos, sem os objetos necessários para a sua realização. As apraxias surgem na lesão de áreas parietais do hemisfério dominante ou no corpo caloso (surgindo, às vezes, apraxias unilaterais, ou seja incapacidade de realizar os atos motores, apenas com uma das mãos).

\subsection{Distúrbios da Gnosia:}

Asterognosia (Holognosia). Agnosia auditiva.

Agnosia táctil. Agnosia visual. Somatognosia.

Agnosia digital (Síndrome de Gerstmann).

Agnosia é a incapacidade de reconhecer objetos pelo tato (agnosia táctil), pela visão (agnosia visual), reconhecer regiões do corpo (somatoagnosia) ou deficiências neurológicas (anosognosia).

Testa-se a gnosia tátil, colocando-se na mão, ora na direita ora na esquerda, objetos corriqueiros (caneta, pente, chave, etc.), permanecendo o examinado de olhos fechados. A gnosia visual é testada, mostrando-se um objeto para ser reconhecido através da visão. As vezes agnosia visual aparece em apenas um dos hemicampos. Depois, pede-se para o paciente reconhecer/nomear as regiões corporais tocadas pelo examinador (cotovelo esquerdo, calcanhar direito, etc), examinando-se assim a somatognosia. Pede-se, ainda, para reconhecer o lado (mão) direito e esquerdo do corpo (confusão esquerda-direita). Às vezes, o paciente não reconhece que está hemiplégico o que lhe traz transtornos sérios, tais como quedas e incompreensão por não realizar determinados atos motores (anosognosia), a qual surge, em geral, na lesão do lobo parietal do hemisfério não dominante.

\section{III - Exame do paciente em coma}

Um paciente em coma, que não colabora, deve ser examinado como qualquer outro, porém, alguns testes adicionais ou substitutivos devem ser feitos.

A inspeção é um item importante neste paciente. Observamos a cor de pele, a presença de traumatismo, salivação sanguinolenta (mordedura de língua $=$ convulsão), respiração, bochechas, posição dos membros e atitude, em geral.

Na lesão do nervo facial, a bochecha do lado lesado se abaula mais quando a expiração é forçada, através da boca semifechada. Um dos membros inferiores poderá estar rodado para fora, indicando paresia deste segmento. O paciente poderá estar em decúbito lateral com o pescoço e tronco estendidos e os membros fletidos (posição em cão de espingarda), indicando meningismo.

O estímulo doloroso é muito importante e se faz, em geral, através de beliscões em áreas do tronco e dos membros. Poderá, algumas vezes, haver resposta motora unilateral (demonstrando uma hemiplegia) ou bilateral. Neste ultimo caso, a resposta à dor poderá ser adequada com retirada do segmento estimulado, global ou ausente indicando coma profundo. A resposta motora global poderá ser com extensão da cabeça, tronco e membros, com pronação dos membros superiores (reação de descerebração) ou com flexão dos antebraços e punhos em frente ao tronco (reação de decorticação). O estímulo doloroso poderá ser útil na demonstração de uma lesão medular pela ausência de respostas à dor, abaixo do nível lesado.

A prova de força muscular, no paciente em coma, é diferente da realizada no paciente consciente. No coma, ergue-se, passivamente, os membros superiores pelos punhos em ângulo de $60^{\circ} \mathrm{com}$ o eixo corporal e observa-se as mãos. Em geral, do lado plégico ela fica mais caída. A seguir, solta-se os membros superiores ao mesmo tempo, o lado plégico cairá mais rápido. 
Outra prova consiste em fletir, passivamente, os antebraços sobre o braço estando este, rente ao corpo e com o cotovelo apoiado no leito. Solta-se os antebraços ao mesmo tempo e, o hemiplégico cairá mais rápido (prova de Raimiste). Nos membros inferiores, dobra-se o joelho, segurando-se os dois pés unidos, apoiados na cama, o membro plégico abduzirá mais rapidamente que o outro.

Para examinar a motricidade ocular faz-se o teste dos olhos de boneca. Num paciente em coma, ao rodar a cabeça para o lado direito o olho direito se posicionará em adução e o olho esquerdo em abdução. O mesmo acontecerá se rodarmos a cabeça para o lado esquerdo, para cima ou para baixo, os olhos sempre tenderão a permanecer, olhando para frente. Detecta-se assim, as deficiências dos nervos oculomotores. Se não houver o fenômeno dos olhos de boneca, o paciente não estará em coma (conversão?) ou o coma estará muito profundo, próximo ou no estado de morte cerebral.

SPECIALI JG Technique of the neurologic examination. Medicina, Ribeirão Preto, 29:19-31, jan./mar. 1996.

ABSTRACT: The autor describes briefly the basic steps os neurologic examination. Main objectives of this work are initiation of undergraduated students, specially of Medicine, in the techniques of neurologic examination and the standardization of these techniques in the University Hospital of the School of Medicine of Ribeirão Preto, Universidade de São Paulo.

UNITERMS: Medical History Taking. Diagnosis, Neurologic. Physical Examination. Neurologic Examination. Neurology.

\section{BIBLIOGRAFIA CONSULTADA}

1 - BICKERSTAFF ER Exame neurológico na prática médica. Trad. JA Levy, S Saraiva \& FM Braga. Atheneu, Rio de Janeiro, $375 p, 1975$.
2 - SANVITO WL. Propedêutica neurológica básica. Manole, São Paulo, 246 p, 1977.

Recebido para publicação em 04/03/96

Aprovado para publicação em 14/03/96 